\title{
Two Apparently Distinct Muscarinic Cholinoceptor Mechanisms in Guinea-Pig Taenia Caecum
}

\author{
Tetsuhiro HISAYAMA, Naomi KUMAGAI and Issei TAKAYANAGI* \\ Department of Chemical Pharmacology. Toho University School of \\ Pharmaceutical Sciences, 2-2-1, Miyama, Furlabashi. Chiba 274, Japan
}

Accepted January 30, 1988

\begin{abstract}
Thirty-min treatment of guinea-pig taenia caecum with $300 \mathrm{nM}$ propylbenzilylcholine mustard (PrBCM) shifted the concentration-response curve for carbachol to the right with a reduction of the maximum contraction, but $90-$ min treatment did not result in further inhibition. Under these conditions, pilocarpine hardly contracted the preparations, and it competitively antagonized carbachol. Muscarinic agonists might interact with two types of receptor mechanisms and carbachol elicited a stimulus from both types, whereas pilocarpine did so predominantly from the $\operatorname{PrBCM}$-sensitive one.
\end{abstract}

Muscarinic cholinoceptors have recently been subdivided into at least two classes, $M_{1}$ - and $M_{2}$-receptors, mainly using nonclassical antagonists such as pirenzepine (1). However, in addition to the subclassification based on these antagonists, heterogeneity of muscarinic agonism has been reported (2-4). This heterogeneity is found in the preparation which predominantly contains one type of receptor as revealed by the use of the antagonists, although evidence for the origin of the heterogeneity is not yet conclusive.

$\mathrm{M}_{2}$-receptors exist predominantly in guinea-pig taenia caecum (our unpublished data), but heterogeneity of muscarinic agonism has not been studied. Propylbenzilylcholine mustard (PrBCM) (5), an irreversible specific muscarinic cholinergic antagonist, has been used increasingly to occlude the receptors. In this communication, we report the effect of treatment with PrBCM on the contractile responses of guinea-pig taenia caecum to carbachol and pilocarpine.

Taenia caecum was obtained from female guinea-pig (300-500 g) and suspended in an organ bath which contained $20 \mathrm{ml}$ of physiological solution of the following composition (mM): $\mathrm{NaCl}, 154 ; \mathrm{KCl}, 5.6 ; \mathrm{MgCl}_{2}$. 2.1: $\mathrm{CaCl}_{2}, 0.8 ; \mathrm{NaHCO}_{3}, 6.0$; and glucose, 2.8. This was kept at $30^{\circ} \mathrm{C}$ and bubbled with

* To whom correspondence should be addressed. air. Carbachol chloride or pilocarpine hydrochloride (both from Sigma Chemical Co.) was applied in the presence of $300 \mathrm{nM}$ tetrodotoxin (Sankyo Co.) using a cumulative technique and the mechanical response was recorded isotonically.

For occlusion of muscarinic cholinergic receptors, after the contral concentrationresponse curve(s) for carbachol or carbachol and pilocarpine was determined, the preparation was treated for $5 \mathrm{~min}$ or longer with $300 \mathrm{nM}$ or $1 \mu \mathrm{M}$ activated PrBCM (New England Nuclear) prepared according to the method of Young et al. (5). When PrBCM was applied for more than $10 \mathrm{~min}$, it was renewed every $10 \mathrm{~min}$. The preparation was then allowed to re-equilibrate for $60 \mathrm{~min}$, with washing every $10 \mathrm{~min}$, and the concentrationresponse curve for carbachol or pilocarpine was determined by repeating determinations of the curves until constant ones were established. For progressive occlusion of the receptors, the same protocol was repeated.

In competition experiments, the preparation was treated with atropine sulfate (Sigma Chemical Co.) or pilocarpine, and in the presence of the drug, the concentrationresponse curve for carbachol was determined. Competitive antagonism was evaluated according to the method of Arunlakshana and Schild (6), and the slope of the Schild plot and $\mathrm{pA}_{2}$ value was calculated by linear 
regression analysis (7).

Figure $1 \mathrm{~A}$ shows the effect of progressive treatments of guinea-pig taenia caecum with $300 \mathrm{nM}$ PrBCM on the carbachol-induced contraction. The concentration-response curve for carbachol was shifted in a parallel fashion to the right after 10-min treatment with activated PrBCM, and treatment for an additional 20 min produced a further displacement of the curve with a slight, but significant reduction of the maximum response. However, more prolonged treatments with PrBCM had no further significant effect on the concentration-response curve. The limiting effect of PrBCM on the concentration-

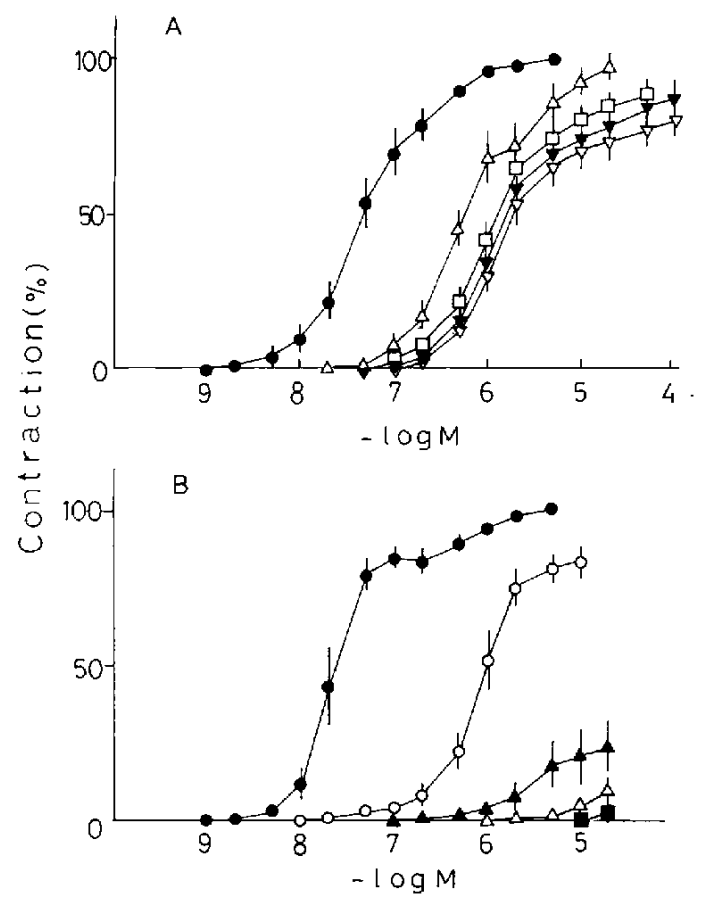

Fig. 1. Effects of progressive treatments with propylbenzilylcholine mustard (PrBCM) on the responses to carbacho! (A) and pilocarpine (B) in guinea-pig taenia caecum. After establishing the control concentration-response curves for carbachol (O) and pilocarpine (O). the preparation was exposed to $300 \mathrm{nM} \operatorname{PrBCM}$ and then washed until a stable concentration-response curve could be obtained. The treatment was then repeated. Cumulative durations of the treatments with $\operatorname{PrBCM}$ were 5 (A), $10(\Delta), 20(\square), 30(\square), 40(\nabla)$ and 50 min $(\nabla)$. Each point represents the mean \pm S.E. of 7 (A) and 6 (B) determinations. response curve for carbachol obtained after treatments using $1 \mu \mathrm{M}$ PrBCM or a single treatment with $300 \mathrm{nM}$ PrBCM for $90 \mathrm{~min}$ was the same as that determined after successive treatments with $300 \mathrm{nM}$ PrBCM for a combined duration of $50 \mathrm{~min}$ (data not shown).

It has been reported that phenoxybenzamine and dibenamine inhibits cellular responses nonspecifically to some degree (8). However, treatment with $\operatorname{PrBCM}$ did not inhibit $\mathrm{KCl}$-induced contraction: EC5O's (negative logarithm of molar concentration to produce $50 \%$ of maximum contraction) of $K$ determined from graphical analyses were $19.3 \pm 0.35$ and $15.9 \pm 0.49 \mathrm{mM}$ in the control and the PrBCM-treated preparations ( 300 $\mathrm{nM}, 50 \mathrm{~min})$, respectively, and the maximum response after the treatment was $107.6 \pm$ $4.0 \%$ of the control $(n=4)$. The result suggests that PrBCM would not inhibit carbachol-induced response by depression of smooth muscle contractility.

Atropine antagonized the response to carbachol of the preparation treated with PrBCM for $50 \mathrm{~min}$ in a competitive manner. The slope of the Schild plot and the calculated $\mathrm{pA}_{2}$ values were $0.91 \pm 0.28$ and $9.06 \pm$ $0.14(n=5)$, respectively. The $p_{2}$ values were not significantly different from those determined in untreated preparations: the values of slope and $\mathrm{pA}_{2}$ were $1.20 \pm 0.37$ and $9.03 \pm 0.13(n=6)$, respectively. In both cases, the slope values of the Schild plot were not different from unity.

Figure 1B shows the effect of treatment with $\mathrm{PrBCM}$ on the concentration-response curve for pilocarpine. The intrinsic activity of pilocarpine was $0.83 \pm 0.04(n=6)$. When the preparation was treated with PrBCM for 5 min, the maximum response to pilocarpine was greatly reduced, and 20 -min treatment almost abolished the response. After 50-min treatment with PrBCM, pilocarpine antagonized the residual response to carbachol in a competitive manner (Fig. 2): the values of the slope of the Schild plot and $p A_{2}$ were $0.97 \pm 0.11$ and $5.67 \pm 0.14 \quad(n=6)$, respectively. The slope value of the Schild plot was not different from unity.

The present study using guinea-pig taenia caecum confirmed that PrBCM irreversibly 


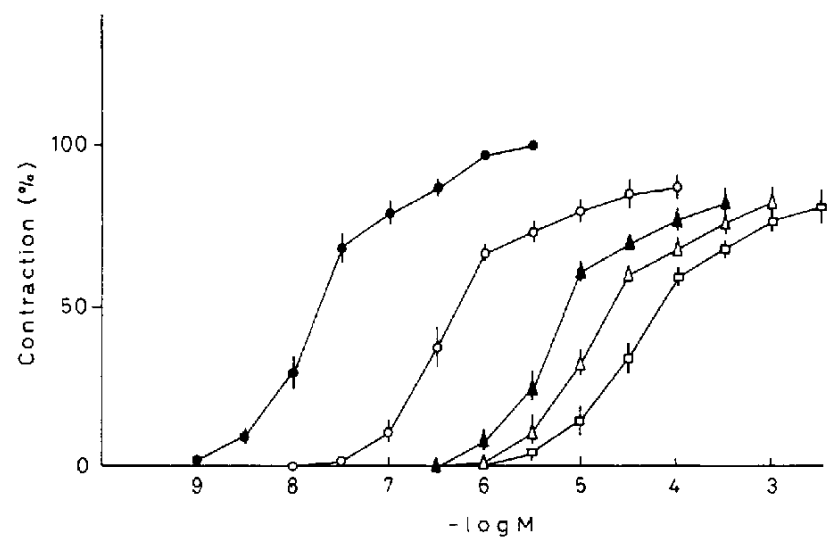

Fig. 2. Effect of pilocarpine on contraction-response curve for carbachol in preparations treated with $300 \mathrm{nM}$ PrBCM for $50 \mathrm{~min}$. : Control curve for carbachol: $\bigcirc . \Delta . \triangle$ and $\square$ : curves for carbachol after $\operatorname{PrBCM}$-treatment in the presence of 0.30 .100 and $300 \mu \mathrm{M}$ pilocarpine, respectively. Each point represents the mean $\pm S$.E. of 6 determinations.

antagonizes the responses to muscarinic agonists (5). However, when carbachol was used as an agonist, it elicits a pharmacological stimulus through the interaction of two distinct, non-interconvertible muscarinic cholinoceptor mechanisms, and PrBCM but not atropine is a selective antagonist which can discriminate between the two. Since the types of muscarinic receptors subclassified so far by use of non-classical antagonists have been reported to be inactivated by $\operatorname{PrBCM}(9)$, the PrBCM-resistant receptors may be a novel type or a special coupling with some factor or effector system(s) may make them PrBCM-resistant.

In guinea-pig taenia caecum, pilocarpine behaved as a partial agonist. Disappearance of the response to pilocarpine by $\mathrm{PrBCM}$ suggests that pilocarpine produces contractions predominantly through activation of PrBCM-sensitive receptor mechanisms. Pilocarpine competitively antagonized the response of the PrBCM-treated preparations to carbachol, suggesting a possibility that pilocarpine actually binds to the PrBCMresistant receptors but does not produce a detectable stimulus.

It has been reported that $\operatorname{PrBCM}$ is selective for some populations of rat heart muscarinic receptors (3) and that the drug cannot inactivate $\left[{ }^{3} \mathrm{H}\right] \mathrm{QNB}$ binding sites of guinea-pig heart completely (4). Therefore. our pharmacological data might provide clues for the finding of unknown receptor subtypes or to an understanding of the mechanisms of receptor-effector coupling. though much additional experimental support such as the difference in Ca-utilization, second messenger systems or dependency on energy metabolism will be required.

\section{References}

1 Hammer, R., Berrie, C.P., Birdsali, N.J.M., Burgen, A.S.V. and Hulme, E.C.: Pirenzepine distinguishes between different subclasses of muscarinic receptors. Nature 283, 90-92 (1980)

2 Burgen. A.S.V. and Spero, L.: The action of acetylcholine and other drugs on the efflux of potassium and rubidım from smooth muscle of the guinea-pig intestine. Br. J. Pharmacol. 58, $613-620$ (1968)

3 Christophe, J., De Neef, P., Robberecht, P. and Waelbroeck, M.: Propylbenzilylcholine mustard is selective for rat heart muscarinic receptors having a low affinity for agonists. Br. J. Pharmacol. 88, 63-70 (1986)

4 Mizushima, A., Uchida, S., Zhou, X.-M., Kagiya, $T$. and Yoshida, $H_{\text {.: }}$ Cardiac $M_{2}$ receptors consist of two different types, both regulated by GTP. Eur. J. Pharmacol. 135, 403-409 (1987)

5 Young, J.M., Hiley, R. and Burgen, A.S.V.: Homologues of benzilylcholine mustard. J. Pharm. Pharmacol. 24, 950-954 (1972)

6 Arunlakshana, O. and Schild, H.O.: Some quantitative uses of drug antagorist. Br. J. Pharmacol. 14, 48-58 (1959)

7 Tallarida, R.J., Cowan, A. and Adler, M.W.: $\mathrm{pA}_{2}$ and receptor differentiation: a statistical analysis 
of competitive antagonism. Life Sci. 25, 637-654 (1979)

8 Gengo, P.J., Yousif, F., Janis, R.A. and Triggle, D.J.: Interaction of phenoxybenzamine with muscarinic receptors and calcium channels. Biochem. Pharmacol. 33, 3445-3449 (1984)
9 El-Fakahany, E.E., Cioffi, C.L., Abdellatif, M.M. and Miller, M.M.: Competitive interaction of pirenzepine with rat brain muscarinic acetylcholine receptors. Eur. J. Pharmacol. 131, 237247 (1986) 